\title{
ENCONTRO DE SABERES: TERRITÓRIOS, RAÇA E GÊNERO
}

\author{
ISABEL SANTANA DE ROSE \\ EDGAR RODRIGUES BARBOSA NETO \\ MARCIO GOLDMAN
}

Este é o segundo volume do dossiê Encontro de Saberes: transversalidades $e$ experiências. O dossiê é resultado de duas reuniões do Seminário Temático de mesmo nome, que aconteceram em 2017 (São Paulo/USP) e em 2019 (Florianópolis/UFSC) ${ }^{1}$. Este seminário, por sua vez, foi motivado pela proposta de criar um espaço plural que possibilitasse um encontro entre alguns dos vários "encontros de saberes", permitindo o estabelecimento de conexões transversais entre essas diferentes experiências. Os dois volumes do dossiê retomam o objetivo do seminário temático. A opção por dividi-lo e publicá-lo em duas partes ocorreu devido a razões de natureza exclusivamente editorial. O primeiro volume, lançado em maio de 2021, contém 11 artigos, enquanto o segundo, que publicamos agora, inclui oito artigos e uma entrevista. Como já afirmamos, "esse conjunto de textos traduz não apenas a heterogeneidade das experiências às quais se referem, mas também maneiras muito diferentes de realizar a sua abordagem e de pensar a partir das relações estabelecidas com elas" (BARBOSA NETO; ROSE; GOLDMAN, 2020, p. 16). Dessa maneira, os dois volumes buscam contemplar e dar visibilidade a essa variedade de experiências, em um momento no qual elas se encontram em um processo de expansão e de consolidação (CARVALHO; VIANNA, 2020).

Cabe reforçar que nosso ponto de partida é uma visão ampliada do que vem sendo chamado de "encontro de saberes". Desse modo, uma das dimensões dessas experiências envolve a inclusão remunerada de mestres e mestras dos saberes tradicionais como professores e professoras de universidades públicas federais e estaduais, um processo que teve início na UnB em 2010 e que recentemente completou uma década. Desde sua implementação, essa experiência se expandiu para pelo menos mais 13 universidades no Brasil, envolvendo um número expressivo de mestres e mestras, das mais diferentes culturas e regiões; de professores e professoras de diversas áreas do conhecimento acadêmico; e de estudantes de graduação e pós-graduação (CARVALHO; VIANNA, 2020). Entretanto, os textos publicados nos dois volumes do dossiê englobam também iniciativas ligadas a outras

\footnotetext{
${ }^{1}$ Recentemente, em novembro de 2021, este ST teve sua terceira edição, também na ReACT, que foi organizada pela UFSCar e aconteceu em formato virtual. Nesta edição contamos com a participação da nossa colega Marina Guimarães Vieira como uma das organizadoras.
} 
políticas de ações afirmativas, tais como reservas de vagas ou vestibular diferenciado para estudantes negros e indígenas, na graduação e na pós-graduação; cursos de natureza intercultural, incluindo licenciaturas indígenas e quilombolas, entre outras. Todas essas intervenções seguramente têm como um de seus aspectos comuns a construção de um meio acadêmico mais diverso, plural e inclusivo. Retomamos aqui, portanto, a ideia de que essa ampliação do sentido da expressão encontro de saberes decorre da "compreensão de que ela constitui uma dimensão fundamental dos processos de inclusão étnico-raciais criados pelas políticas de ações afirmativas implementadas nos últimos vinte anos pelas universidades brasileiras" (BARBOSA NETO; ROSE; GOLDMAN, 2020, p. 12). Consideramos, assim, que "a reflexão sobre os encontros de saberes se situa dentro de um processo mais amplo de transformação das universidades, no qual, entre outros fatores, tem destaque um ingresso cada vez maior de estudantes negros, negras e indígenas na graduação e na pósgraduação" (BARBOSA NETO; ROSE; GOLDMAN, 2020, p. 12-13).

Na apresentação do primeiro volume, fizemos uma reflexão mais aprofundada sobre algumas das diferentes experiências de encontro de saberes, incluindo seu histórico e contexto, assim como alguns dos seus vários desdobramentos. Os textos que compõem este volume também demonstram que estamos, de um lado, diante de transformações propriamente institucionais e, de outro, da recriação dos meios pedagógicos, possibilitando a abertura de novos caminhos para as práticas de pesquisa, extensão e ensino. A primeira apresentação engloba ainda uma reflexão sobre a própria noção de "encontro" e suas diversas dimensões ou lados, incluindo seus riscos, como a romantização, a exotização e a tolerância, mas também suas potencialidades, como a capacidade de "criar outros possíveis para a universidade", fortalecendo os movimentos de resistência à "lógica colonialista e neoliberal que se mostra enraizada em suas práticas" (BARBOSA NETO; ROSE; GOLDMAN, 2020, p. 16). Na introdução a este segundo volume, retomamos parte dessas questões e nos concentramos em reflexões elaboradas a partir dos trabalhos aqui reunidos, procurando apresentar os textos por meio dos debates e dos temas que eles ajudam a tornar mais visíveis.

Como indicam vários dos trabalhos publicados aqui, as políticas de ações afirmativas no ensino superior têm uma série de desdobramentos fundamentais, incluindo a demanda por novas formas de ensinar e aprender, outros meios de acolhimento universitário e ainda outras formas de administrar os recursos financeiros da universidade. Nesse sentido, Yérsia Souza de Assis e Larisse Pontes Gomes chamam a atenção para a necessidade de "redimensionar a educação brasileira através da experiência racial" e afirmam que, no contexto dessas transformações, uma recorrência é a exigência de ementas e currículos mais ligados a pautas étnico-raciais, de gênero e sexuais. De maneira semelhante, Marina Guimarães Vieira, Jade Alcântara Lôbo e Sueli Maxakali questionam uma metodologia de 
ensino "tradicional brancocêntrica" e denunciam o baixíssimo número de professores e professoras negros e indígenas nas instituições de ensino superior no Brasil de modo geral, e na antropologia em particular, o que, de acordo com elas, contribui para constituir a academia como um "lugar de opressão colonial". Assis e Gomes afirmam ainda que as demandas dos(as) discentes que ingressam na pós-graduação por cotas englobam tanto políticas de permanência quanto aspectos formativos, ligados à necessidade de "pensar uma sala de aula mais inclusiva", levando em conta a interseccionalidade entre raça, classe, etnia e gênero. Nessa mesma linha, Pablo Albernaz e Letícia Ponso abordam o encontro de saberes como um desdobramento da criação e ampliação das políticas de ações afirmativas para ingresso no ensino superior no Brasil, o que traz novas demandas, como a inclusão das formas de pensar nas línguas, culturas e cosmologias dos(as) estudantes que ingressam por cotas, bem como a promoção de "práticas institucionalizadas que promovam transformações na política de sua permanência na universidade, mas também transformações na estrutura da própria universidade".

Levando em conta essas reflexões, uma questão que possivelmente ficou mais evidente neste segundo volume diz respeito ao protagonismo feminino nas diferentes experiências de encontro de saberes, englobando a autoria e produção de conhecimento feminina, bem como a presença de mulheres negras e indígenas na pós-graduação e na universidade de modo mais geral. Isso nos leva a sugerir que o debate sobre a presença e o protagonismo feminino nessas experiências precisa ser mais aprofundado e ter mais visibilidade, assim como a discussão sobre as assimetrias de gênero, raça e classe no contexto acadêmico. Somado ao fato do dossiê, nos seus dois volumes, conter um número expressivo de autoras mulheres, em muitos casos as mestras dos saberes tradicionais aparecem como as protagonistas principais dos textos. Em vários dos relatos presentes neste volume, como é o caso dos trabalhos de Luciana Oliveira, Victor Miranda e Laura de Castro e Cacá Fonseca, essas mestras chamam a atenção para as estreitas relações entre os seus saberes tradicionais e territórios específicos, o que inclui as lutas para retomar e garantir esses territórios. Mulheres como a professora, coordenadora pedagógica e artista gráfica e têxtil Rita Pataxó (Aldeia Kaí, Cumuruxatiba, BA); a pajé Japira Pataxó (aldeia Novos Guerreiros, localizada entre Porto Seguro e Santa Cruz Cabrália, BA); e a xamã kaiowá Tereza Flores (tekoha Guaiviry Yvy Pyte Y Jere, Aral Moreira, MS) nos mostram que o caráter territorializado dos saberes tradicionais está vinculado à defesa dos territórios e aos movimentos pela sua retomada, dos quais elas são protagonistas fundamentais. Ao mesmo tempo, algumas das autoras e autores indicam que uma das possibilidades de transformação trazida pelo encontro de saberes envolve o enraizamento das próprias universidades nos territórios nos quais se encontram, tanto quanto o estabelecimento de relações com as comunidades de seu entorno. 
Uma questão transversal a muitos dos trabalhos publicados neste volume envolve as possíveis conexões e confluências, mas também os impasses, equívocos e riscos, presentes nos encontros e relações entre distintos modos de transmissão de conhecimento, muitas vezes classificados como "acadêmicos" e "tradicionais". Este debate está diretamente ligado ao tema da escrita ou grafocentrismo que predomina nos contextos acadêmicos, em contraste com os saberes tradicionais que, via de regra, são marcados pela oralidade, pela corporalidade, pelos afetos e pela práxis. Vários dos textos presentes aqui falam de diferentes maneiras sobre as possibilidades e limites nas traduções, passagens e deslocamentos entre saberes tradicionais e escrita. Laura Castro e Cacá Fonseca citam Ailton Krenak, que nos lembra que historicamente a leitura e a escrita serviram como instrumento de colonização e como produtores e reprodutores de assimetrias. Já Victor Miranda, que parte dos escritos da pajé Japira Pataxó, argumenta que "os saberes das mestras e mestres das tradições ameríndias, negras e populares são frutos de espaços de aprendizagem muito distintos daqueles que elegemos como centros de produção e transmissão do conhecimento", o que envolve encontrar metodologias de ensino também distintas. Lembrando uma fala recorrente de Antônio Bispo dos Santos, que sempre afirma que as coisas têm "começo, meio e começo" e chama a atenção para o caráter circular das cosmologias dos povos politeístas (BISPO DOS SANTOS, 2015), Miranda sugere que os saberes tradicionais são pautados mais por uma lógica da circularidade do que da linearidade (como aquela presente, de modo geral, nos livros e nos textos). Nesse sentido, de acordo com ele, as aulas dos mestres e mestras dos saberes tradicionais nas universidades muitas vezes seguem uma "abordagem circular do saber". Somado a isso, para este autor, esses saberes têm outras temporalidades e requerem o desenvolvimento da capacidade de escuta e da contemplação.

Como já indicamos, vários dos textos presentes neste volume tratam da necessidade de transformações abrangentes em termos institucionais, pedagógicos e epistemológicos nas universidades, impulsionadas tanto pelas políticas de ações afirmativas de modo mais amplo quanto pelo encontro de saberes propriamente dito. Neste âmbito, um tema emergente, presente principalmente no artigo de Bruno Goulart, diz respeito à outorga de títulos de Notório Saber para os mestres e mestras. A discussão está estreitamente ligada à necessidade de remuneração dos mestres e mestras dos saberes tradicionais pela sua participação em atividades nas universidades, assim como aos limites institucionais e burocráticos para a efetiva contratação desses mestres(as) como professores, o que muitas vezes passa pela questão da titulação. Em termos mais amplos, o debate envolve impasses relacionados aos diferentes critérios e parâmetros presentes nos contextos acadêmicos e nos contextos dos saberes tradicionais para reconhecer os conhecimentos e seus detentores. Nesse cenário, algumas universidades vêm buscando 
construir caminhos para esse reconhecimento que contemplem a especificidade dos mestres, mestras e seus saberes.

Os primeiros três textos do dossiê, de Laura Castro e Cacá Fonseca; Victor Miranda; e Augustin de Tugny, Alessandro Facundes Bezerra, Daniel Durans, Leonardo Holanda e Márcio de Almeida Costa tratam de experiências de inclusão de mestres e mestras dos saberes tradicionais como docentes no contexto da Universidade do Sul da Bahia (UFSB). Esta recorrência sem dúvida está ligada a uma particularidade da UFSB, pois a própria criação desta universidade foi pautada em ideias como interdisciplinaridade e interculturalidade e pelo propósito de construir uma instituição pluriepistêmica e decolonial. Somado a isso, outra proposta importante da UFSB é a interiorização do ensino superior público e o desenvolvimento regional, o que implica estabelecer relações entre os cursos e as especificidades e demandas locais. Nesse sentido, a proposta inicial da UFSB envolvia incluir o encontro de saberes na estrutura curricular do curso. Mais especificamente, os três textos abordam a participação de diferentes mestres e mestras no Atelier Encontro de Saberes, um espaço voltado para os alunos e alunas do bacharelado e da licenciatura intercultural em artes desta universidade e que, de acordo com Laura Castro e Cacá Fonseca, envolvia a "construção de processos e projetos artísticos dos estudantes a partir do encontro com mestres e aprendizes de comunidades tradicionais, com investigações teórico-práticas sobre seus sistemas estéticos". Estas autoras afirmam ainda que "na prática havia, portanto, um campo aberto de possibilidades para experimentar outros saberes, assim como questionar o conhecimento universitário eurocêntrico, uma vez que boa parte dos componentes curriculares dialogavam com poéticas e estéticas ameríndias e afrobrasileiras".

O texto de Laura Castro e Cacá Fonseca que abre este dossiê aborda os múltiplos encontros e seus desdobramentos, incluindo a reflexão sobre "tudo que é possível ver acontecer a partir do encontro". Os diferentes atores que compõem os encontros descritos no artigo incluem professores e estudantes do ensino superior e básico, uma rede de artistas de um coletivo gráfico não indígena, e a comunidade de um colégio estadual indígena das comunidades pataxó do sul da Bahia. Estes grupos e coletivos distintos se reúnem em um projeto de extensão voltado para a produção de materiais didáticos em escolas indígenas, chamado "Edições Zabelê", que tinha como objetivo inicial produzir um livro coletivo, tendo a escola e a comunidade indígena como os protagonistas da publicação, juntamente com as histórias de seu território. Somado a isto, uma protagonista fundamental no artigo é Rita Pataxó, como vimos, professora, coordenadora pedagógica, artista gráfica e têxtil e "artesã de múltiplas linguagens contemporâneas e ancestrais". As autoras contam como o primeiro contato delas com a comunidade da escola indígena aconteceu no início de 2016, quando a aldeia tinha acabado de sofrer uma reintegração de posse violenta que havia destruído todas as ocas, casas, plantações e o posto de saúde, com exceção da escola. Depois dessa 
destruição, aconteceu uma retomada do território protagonizada pelas mulheres. Foi nesse contexto que elas buscaram desenvolver ações junto ao colégio como uma forma de contribuir na luta para assegurar o território, elegendo a "tática transversal" de fazer um livro no âmbito de um projeto de extensão com a comunidade escolar. O processo pedagógico e criativo impulsionado por esses encontros envolveu a criação de um alfabeto, o Atxúhu, tendo como ponto de partida os carimbos desenvolvidos por Rita Pataxó. Posteriormente, este alfabeto foi transformado em uma fonte de computador que, finalmente, "foi a grande guia do texto do livro que viria a nascer". Castro e Fonseca argumentam que se tratou de um encontro que envolveu um movimento de "contracolonização epistêmica", numa conjuntura em que "a universidade participa, mas não é ela quem conduz os conhecimentos, muito pelo contrário". Partindo daí, elas sugerem uma "expansão filosófica da ideia de troca", que envolve um deslocamento da troca como intercâmbio para a troca como metamorfose, englobando a prática da reciprocidade e da partilha.

O artigo de Victor Miranda tem como protagonista central a pajé Japira pataxó, que vive na aldeia Novos Guerreiros, localizada entre Porto Seguro e Santa Cruz Cabrália (BA), e que é "uma sabedora das tradições e tecnologias do povo Pataxó, sendo mestra da cura e do cuidado". Japira participou de diferentes experiências do encontro de saberes no contexto da UFSB, incluindo cursos voltados para os estudantes de saúde e de artes, além de ter ministrado encontros pedagógicos na escola indígena em Coroa Vermelha (BA). O texto está centrado na discussão sobre o livro da mestra, e principalmente sua introdução, escrita pela própria Japira e onde ela "aponta importantes discussões acerca de sua metodologia de ensino e sobre como aprendeu seus saberes". Partindo daí, Miranda procura refletir sobre três instâncias de transmissão dos saberes que aparecem no texto da mestra: a primeira envolve o aprendizado dos saberes medicinais através dos anciões pataxó; a segunda está ligada às formas pelas quais a própria mestra Japira tramite este saber; e, finalmente, outro espaço se dá através do livro. Nesse contexto, o autor chama atenção para um estreito vínculo entre a transmissão da sabedoria da oralidade, a experiência, a escuta e a memória. De acordo com ele, trata-se de uma pedagogia que toma como ponto de partida o "par experiência/sentido", que "tem o corpo como importante instância de investigação" e ainda como um "lugar central de elaboração de conhecimentos". Como vemos também no caso dos saberes de Rita Pataxó, mencionado acima, Miranda ressalta a íntima vinculação dos saberes de Japira sobre as plantas medicinais pataxó ao seu território. O autor ressalta que "esse saber, profundamente territorializado, não está dissociado da defesa desse território", sendo que tanto a mestra Japira quanto seu companheiro, o cacique Jonga, foram atores fundamentais no processo de retomada das terras pataxó na região onde vivem. Miranda sugere que as aulas ministradas pela mestra Japira contribuíram para produzir entre os alunos e alunas "outro entendimento do território sul baiano, marcado pela incansável luta 
do povo pataxó contra os processos colonizatórios". O autor enfatiza, portanto, a capacidade do encontro de saberes de contribuir para enraizar as universidades nos territórios onde estas estão localizadas em um movimento que teria um caráter decolonial.

O trabalho de Augustin de Tugny, Alessandro F. Bezerra, Danial Durans, Leonardo Holanda e Márcio de Almeida Costa aborda a participação do mestre Ibã Huni Kuin no Atelier Encontro de Saberes da UFSB em 2016. Com base nos depoimentos do próprio Ibã, os autores observam que este mestre tem uma dupla formação. Dentro da cultura tradicional huni kuin ele se especializou no âmbito da prática xamânica e dos cânticos do nixi pae (ayahuasca). Já no contexto não indígena ele se formou como professor, tendo realizado pesquisas sobre os conhecimentos do povo Huni Kuin que resultaram em várias publicações de sua autoria. Desse modo, uma questão muito interessante na trajetória de lbã está no desenvolvimento de estratégias de "passagem entre a cultura huni kuin e as culturas urbanas". Uma dessas estratégias é a transcrição dos cantos do nixi pae através do desenho e da pintura, desenvolvida por Ibã e outros Huni Kuin mais jovens e que, para Augustin et. al, constitui "uma verdadeira operação de tradução intersemiótica". Este projeto se vincula à fundação do coletivo MAHKU, Movimento dos Artistas Huni Kuin, que visa contribuir para a valorização do povo Huni Kuin e de sua arte frente à sociedade envolvente. Trata-se de uma estratégia de reconhecimento que tem tido bastante sucesso, tendo levado à apresentação de artistas do MAHKU e de seus trabalhos em diversas exposições e eventos, tanto dentro quanto fora do Brasil. Nesse sentido, os autores argumentam que a empreitada de lbã à frente do MAHKU o coloca como um "passador entre culturas, particularmente propício a fomentar encontros de saberes". O texto discute ainda os processos artísticos desenvolvidos pelos estudantes na UFSB depois da visita de Ibã, trazendo as reflexões de quatro alunos a respeito de suas experiências com o mestre, muitas vezes pensadas em relação com a própria prática artística e musical.

Os próximos dois textos, de Marina Guimarães Vieira, Jade Alcântara Lôbo e Sueli Maxakali, e de Yérsia Souza de Assis e Larisse Pontes Gomes, apresentam outras questões, incluindo um debate fundamental sobre gênero, interseccionalidade e a presença de mulheres negras e indígenas nos espaços universitários. O trabalho de Vieira, Lôbo e Maxakali parte de experiências ligadas a uma disciplina realizada no Departamento de Antropologia da UFBA que enfocou trabalhos de autoria indígena, afro-brasileira e africana, contando com o protagonismo de estudantes cotistas negras, quilombolas e indígenas; e uma disciplina que envolveu a participação de mestras e mestras dos saberes artes e ofícios, bem como de jovens lideranças periféricas, tendo sido oferecida durante três semestres, também na UFBA. As duas experiências tiveram em comum a tentativa de trazer para a universidade discussões dentro da temática das relações afroindígenas e da educação para as relações étnico-raciais. Mais ainda, trata-se de um texto etnográfico escrito por "uma 
professora socialmente lida como branca, uma doutoranda negra e uma professora indígena". Nesse sentido, o artigo constitui um experimento de co-autoria entre três acadêmicas que partem de lugares de fala muito diferentes, principalmente no que diz respeito às relações étnico-raciais. Outra questão central que atravessa o trabalho, e que ao mesmo tempo conecta e diferencia as autoras, é a maternidade. A tentativa de pensar essas diferenças envolve experimentações na própria escrita, buscando demarcar qual das autoras está falando em determinadas passagens do texto e ressaltando que essa escrita heterogênea parte de corpos diferentes e de perspectivas distintas. Paralelamente, Vieira, Lôbo e Maxakali afirmam que "o que nos aproxima é a impossibilidade de ocuparmos, com nossos corpos, práticas de conhecimento e pensamentos, a posição hegemônica do 'nós' acadêmico universal - homem hétero, branco, ocidental". Trata-se, de acordo com elas, de um "experimento de contra-colonização dentro da academia, ao adotarmos metodologias ancoradas em múltiplas vozes". As autoras recusam ainda a ideia de um "objeto" de pesquisa, com seu pressuposto do distanciamento, propondo fazer uma "pesquisa centrada em sujeitos" que evidencie o "compartilhamento de conhecimentos heterogêneos".

Já o texto de Yérsia Souza de Assis e Larisse Louise Pontes Gomes, escrito por duas mulheres negras, traz uma contribuição fundamental para pensar o encontro de saberes em termos mais amplos ao enfocar as políticas de ações afirmativas no ensino superior no Brasil, em especial aquelas de reserva de vagas para estudantes negras e negros na pós-graduação. A primeira parte deste artigo aborda as políticas de cotas e o programa de ações afirmativas, descrevendo a sua contribuição para modificar o ensino superior brasileiro. Neste sentido, as autoras lembram que, enquanto em algumas universidades públicas brasileiras a implementação das políticas de cotas na graduação está completando uma década ou mais, a introdução de reserva de vagas e políticas de ações afirmativas na pós-graduação é bem mais recente, refletindo e reproduzindo desigualdades educacionais e exclusões raciais. Posteriormente, Assis e Gomes fazem uma reflexão em primeira pessoa falando sobre suas escrevivências e experiências como alunas negras num programa de pós-graduação situado no sul do Brasil, uma região comparativamente marcada pela falta de políticas de ações afirmativas. Larisse Gomes conta sobre sua experiência de vida e trajetória intelectual enquanto mulher negra e nordestina, mencionando os deslocamentos que aconteceram entre a graduação em ciências sociais na UFAL e o ingresso no mestrado em antropologia na UFSC, por meio da política de cotas, quando mergulhou no campo das relações raciais e da negritude. Yérsia Assis também fala a respeito de sua trajetória intelectual, incluindo a pesquisa de mestrado realizada na UFS, que teve como tema as cotas nos cursos de medicina e direito dessa universidade. Nesse contexto, a autora relata como diversas vezes foi confrontada por seus interlocutores docentes a respeito da validade e legitimidade de sua investigação, pelo fato de ser uma mulher negra pesquisando ações afirmativas. Ao longo de 
todo o texto, as autoras destacam a importância das cotas no processo de implementação das ações afirmativas no país, apontam para as mudanças que este processo traz para as universidades, e sugerem que o caráter transformador dessas políticas transcende os sujeitos individuais contemplados, abarcando e atingindo uma rede de relações mais ampla de pessoas negras "que passam a vislumbrar outros horizontes e a cogitar outras possibilidades". Elas indicam que a reflexão sobre as ações afirmativas e seus desdobramentos cabe para todos os campos de saber, mas enfocam principalmente a antropologia, seus avanços e limites frente a essas iniciativas.

Os dois textos seguintes, de Pablo Albernarz e Letícia Ponso e de Bruno Goulart, retomam as discussões sobre a inclusão de mestres e mestras dos saberes tradicionais como docentes nas universidades, ressaltando os desafios institucionais enfrentados nessas experiências. O trabalho de Albernaz e Ponso faz um relato sobre o processo de implementação recente do encontro de saberes em duas universidades situadas em diferentes extremos do país: a Universidade Federal de Roraima (UFRR), no extremo norte; e a Universidade Federal do Rio Grande (FURG), no extremo meridional. Eles indicam que, apesar de uma tendência crescente da institucionalização deste projeto, as experiências nestas duas universidades ainda se restringem a iniciativas pontuais de alguns cursos e professores(as). Pensando sobre as transformações institucionais e pedagógicas impulsionadas por essas iniciativas, os autores argumentam que frequentemente as tentativas de criar propostas pedagógicas interculturais nas universidades encontram desafios devido à "estrutura acadêmica predominantemente monocultural e monológica, pouco flexível no que tange à absorção de experiências outras, distintas dos padrões normativos do sistema nacional de educação superior". Desse modo, para Albernaz e Ponso, de maneira geral a academia continua sendo refratária às transformações estruturais que a presença desses grupos demanda. Outra necessidade relevante destaca pelo texto é o preparo que os(as) docentes devem ter para acompanhar as mudanças que estão em curso nas IFES brasileiras ao longo das últimas três décadas, vinculadas aos crescentes debates sobre a plurivocalidade e a diversidade. Os autores argumentam que as etapas para assumir uma política de ação afirmativa em uma instituição de ensino superior incluem a desconstrução da ideia equivocada de "democracia racial", uma mudança no perfil da produção do conhecimento e um amplo debate sobre a colonialidade do saber e do poder.

O texto de Bruno Goulart enfoca a emergência nas universidades brasileiras de debates sobre a outorga de títulos de notório saber para os mestres e mestras dos saberes tradicionais, discussão que vem ganhando maior visibilidade ao longo dos últimos dez anos. Ele propõe apresentar um levantamento e uma reflexão sobre esses processos, pensando sobre os caminhos que têm sido adotados em diferentes instituições para o reconhecimento dos mestres e mestras. Para Goulart, este não é um movimento isolado, mas se encontra 
relacionado com outros fatores recentes, como a disseminação dos conceitos de mestres e mestras tradicionais nas políticas públicas culturais, vinculada aos debates sobre patrimônio imaterial; e o surgimento de projetos e propostas de inclusão desses sujeitos e seus saberes no ensino superior, principalmente a partir de 2010. Nesse contexto, e tendo em vista os obstáculos institucionais mencionados em diversos trabalhos presentes neste dossiê, o debate sobre a outorga dos títulos de notório saber emerge "como um modo de reconhecer e equiparar institucionalmente os saberes dos mestres e mestras com os acadêmicos". Nesse âmbito, um dos principais desafios diz respeito a como encontrar caminhos para este reconhecimento institucional e titulação que respeitem e "contemplem a especificidade dos mestres, mestras e seus saberes", deslocando os critérios e parâmetros hegemônicos, baseados na pontuação da produção acadêmica. Como mostra Goulart, em algumas instituições a via escolhida tem sido a adoção do formato do memorial descritivo ou história de vida como uma forma de comprovação do direito ao título. Apesar de mostrar alguns pontos de aproximação entre os debates e resoluções ligados ao notório saber em diferentes universidades, Goulart também indica que os trâmites administrativos seguem caminhos distintos e devem ser pensados e compreendidos contextualmente.

Fechamos este dossiê com o artigo de Luciana Oliveira, que traz como protagonistas o casal de xamãs kaiowá Valdomiro Flores (falecido em 2017) e Tereza Amarília Flores, atores fundamentais no processo de retomada da tekoha Guaiviry, localizada no Mato Grosso do Sul. Valdomiro e Tereza ministraram três disciplinas na UFMG entre 2014 e 2018, no contexto da Formação Transversal em Saberes Tradicionais, nas quais estes só falaram guarani e tiveram tradução simultânea por assistentes bilíngues indígenas. Não por acaso, Oliveira descreve o casal como "lideranças espirituais comprometidas com a luta pela reconquista dos territórios tradicionais", que "sempre entenderam o xamanismo como forma de reconquista do diálogo com os parentes da 'terra de cima'". Este é um dos aspectos que fundamenta o movimento de retomada dos territórios no contexto do Mato Grosso do Sul, região caracterizada por uma "guerra histórica de longa duração", bem como pelo genocídio contínuo do povo kaiowá, abordado no texto a partir do conceito de necropolítica (MBEMBE, 2017). A autora enfatiza que, ao atuarem tanto na universidade quanto no tekoha Guaiviry, "Valdomiro e Tereza sempre falaram de uma aliança possível entre nós" (indígenas e não indígenas). Outra narrativa recorrente nas falas desses mestres kaiowá estava ligada à importância da reza, como forma de evitar o fim do mundo. Oliveira indica que, nos seus encontros com o casal, tanto na universidade quanto no território indígena, eles sempre enfatizaram as diferenças no modo de ser dos Kaiowá e dos não indígenas, indicando que haveria uma incompatibilidade incontornável entre estes dois modos de vida. Tendo isto em vista, uma das questões levantadas no texto diz respeito a "como pensar, então, a aliança entre intelectuais brancas e intelectuais indígenas, entre universidade e comunidades de 
saberes tradicionais"? Oliveira sugere que "a aliança é possível se nós, desde um lugar de afirmação das reparações históricas e da justiça epistêmica utópica, nos colocarmos a tarefa de sermos produtores de presença. E produzir a presença envolve muitos gestos de acolhimento e coabitação"; "envolve cuidado e respeito".

Рara nós estas discussões, presentes nos textos e sistematizadas nessa apresentação, levantam uma série de perguntas, que não pretendemos responder, mas gostaríamos de deixar abertas, ressoando ao longo da leitura deste dossiê: como abordar os saberes "tradicionais" e "acadêmicos"/"científicos" de uma forma que não seja dicotômica e estanque? Como manter o caráter dinâmico e criativo e a heterogeneidade que está presente nos saberes tanto "tradicionais" quanto "científicos", ao mesmo tempo sem esquecer que existem diferenças importantes entre eles? Como colocar esses diferentes saberes e modos de transmissão do conhecimento em relação - ou como promover encontros - sem que a lógica dominante ou sobrecodificadora seja sempre aquela que vem da ciência ocidental, historicamente eurocêntrica, racista, neoliberal e excludente? Também gostaríamos de destacar a importância de articular as reflexões sobre encontro de saberes, em suas diferentes dimensões, sobre debates mais amplos a respeito de gênero, raça e interseccionalidade.

\section{REFERÊNCIAS}

BARBOSA NETO, Edgar R.; ROSE, Isabel S. de; GOLDMAN, Marcio. Encontros com o encontro de saberes. Revista Mundaú, v. 1, n. 9, p. 12-22, 2020.

BISPO DOS SANTOS, Antonio.Colonização, quilombos. Modos e significações. Brasília: INCTI, 2015.

CARVALHO, José J.; VIANNA, Letícia C. R. 0 Encontro de Saberes nas universidades. Uma síntese dos dez primeiros anos. Revista Mundaú, v. 1, n. 9, p. 23-49, 2020.

MBEMBE, Achille. Necropolítica. São Paulo: no.1 Edições, 2018. 